\title{
Knowledge Level and Associated Factors of Reproductive Health Issues among Secondary School Students in Woldia Town, Amhara, Ethiopia, 2019: A Cross-Sectional Study
}

\author{
Biruk Beletew Abate ${ }^{D}$, Kalkidan Habtamu Gelaw, Hayelom Fentaw, Mekonen Ashagire, \\ and Tadesse Mekash
}

Department of Nursing, Faculty of Health Sciences, Woldia University, P.O. Box 400, Woldia, Ethiopia

Correspondence should be addressed to Biruk Beletew Abate; birukkelemb@gmail.com

Received 31 March 2020; Revised 25 September 2020; Accepted 13 October 2020; Published 22 October 2020

Academic Editor: Animesh Jain

Copyright (c) 2020 Biruk Beletew Abate et al. This is an open access article distributed under the Creative Commons Attribution License, which permits unrestricted use, distribution, and reproduction in any medium, provided the original work is properly cited.

\begin{abstract}
Background. Reproductive health (RH) is defined as a state of complete physical, mental, and social wellbeing and not merely the absence of disease or infirmity, in all matters related to the reproductive system and to its functions and process. Local evidence about adolescents' reproductive health knowledge level and associated factors are relevant to design age-appropriate interventions strategies. Therefore, the aim of this study was to assess the knowledge level on reproductive health issues among secondary school students in Woldia town. Objective. The main aim of this study was to assess the knowledge level and associated factors among adolescents in Woldia secondary schools, Amhara, Ethiopia, 2019. Methods. Institution-based descriptive cross-sectional study was conducted on 420 secondary school students in Woldia town from January to June 2019. Multistage sampling technique was employed. A self-administered, structured, and adapted questionnaire was used to collect the data. The data was entered by using EpiData version 4.2 and exported to SPSS version 24.0 for analysis. The samples were distributed proportionally based on probability proportional to size (PPS) allocation technique. Participants in each school have been selected by using systematic sampling technique after calculating sample interval $(K)$ for each school. Bivariate and multivariable logistic regressions were carried out to assess the association between dependent and independent variables. Result. The prevalence of good knowledge was 204 (48.6\%). Residence, educational level, handling of RHS providers, ever gone RHS institution and missed RHS service, had RHS in school, and stigma to utilize RHS were found to be significantly associated with the level of knowledge of respondents on reproductive health issues. Conclusion and Recommendations. The knowledge of respondents on reproductive health issues in the study area was found to be low. Hence, it is better to improve access to information to the secondary school students on RHS through trained health workers and accessible RHS.
\end{abstract}

\section{Background}

Reproductive health $(\mathrm{RH})$ is defined as a state of complete physical, mental, and social wellbeing and not merely the absence of disease or infirmity, in all matters related to the reproductive system and to its functions and process. An adolescent is defined as a person aged between 10 and 19 years of age [1]. They account for $22 \%$ of the total population of Ethiopia [2].

Reproductive health is a universal concern, but is a special importance for women particularly during reproductive years [3]. It addresses the human sexuality and reproductive processes at all stages of life and implies that people are able to have a responsible, satisfying, and safe sex life and that they have the capability to reproduce and the freedom to decide if, when, and how often to do so. Youths and adolescents are characterized by unique physical, psychological, social, and emotional changes that put their life at high risk [2].

The term Youth Friendly Reproductive Health Service (YFRHS) refers to those services that are accessible, acceptable, and appropriate for the youth such as counseling, 
family planning, Voluntary Counseling and Testing (VCT), and treatment of Sexually Transmitted Infections (STI) [4]. The services are provided in line with the minimum health package and aims to increase acceptability and use of health services by young people [5]. Youth friendly services emphasize sexual and reproductive health counseling, contraceptive counseling and provision (including emergency contraception), STI prevention, HIV counseling and testing, treatment and care, prenatal and postpartum care, sexual abuse counseling, relationship counseling, and safe abortion and abortion-related services [6].

Currently, there is a low level of access to high-quality RH information and services, especially for adolescents [7]. In the past few years, the issues of RH have been increasingly perceived as a social problem; they have been emerging as a topic of increasing concern in both developed and developing countries [8]. Adolescents are not quite capable of understanding complex concepts. This makes them vulnerable to sexual exploitation and high-risk sexual behaviors and reproductive health problems [9].

Globally, 45 percent of all new HIV infections worldwide are occurring among young people aged 15 to 24 years; 500,000 young people are infected with an STI per day. Approximately 80 million women have unwanted pregnancies every year $[10,11]$. Adolescent girls are considerably more likely to be infected than adolescent boys [12]. Many adolescents are less informed, less experienced, and less comfortable accessing health services for RH than do adults [13]. Moreover, there are unsafe abortions by young women aged 15-24, 45 percent, their fertility rate is high (116 percent), and the level of comprehensive knowledge of AIDS is 48 percent for young women aged 15-24 and 43 for young men aged 15-24 [4]. Young people in high schools and above are vulnerable and at risk to HIV infection due to various reasons (such as unprotected casual sex relationships and multiple sexual partners, lack of comprehensive knowledge about HIV/AIDS, sexual and reproductive health, lack of access to HIV services, sexual experimentation, early sexual debut and peer pressure, and other related factors) [14].

In Africa, 430,000 young people are infected with HIV per year; 2.6 million young people are living with HIV; and teenage pregnancy rates still remain high, and maternal mortality is among the leading causes of death for adolescent girls in this region [15].

The intergenerational gap between the generations of the youth and the adult is constantly being reinforced by cultural globalization. The comprehensive knowledge of HIV and other reproductive health $(\mathrm{RH})$ problems is increasing; many young people do not have the information or means to protect themselves from these problems [16]. There are also problems related to SRH services which include accessibility, availability, and quality. Moreover, secondary school students indicated that health providers in most of the HEIs are not trained to respond to the needs of young persons [17]. The shortage of youth friendly health services and counseling poses significant challenges to address SRH issues, including HIV prevention.
In Ethiopia, educational institution-based $\mathrm{RH}$ services are often limited by restrictive policies, personnel shortages, lack of private areas for counseling, and poor links to resources outside the institutions. The problems of HIV/AIDS and other sexually transmitted infections (STIs) among youths indicating more efforts are needed toward sexual and reproductive health risk reduction interventions particularly in secondary school student. Hence, the main aim of the study was to assess the knowledge secondary school students on reproductive health issues in Woldia town.

\section{Methods}

2.1. Study Area and Period. This study was conducted in Woldia town from January to June 2019. Woldia town is located in the northeast Ethiopia Amhara regional state under the administration of North Wollo Zone, which is located at about $521 \mathrm{~km}$ from Addis Ababa in the west direction. This town has nine kebeles and four secondary schools. The study was conducted in all secondary schools, namely, Woldia secondary school, Millennium secondary school, Selam secondary school, and Gubo secondary school.

2.2. Study Design. The study design was institution-based descriptive cross-sectional study.

2.3. Source of Population. The source of population included all secondary school students in Woldia town.

2.4. Study Population. The study population involved all selected students of Woldia town secondary school.

2.5. Sample Size Determination. The sample size of the study was calculated using single proportion population formula as $n=\left(\mathrm{Z}^{2} \alpha / 2 * \mathrm{P}(1-\mathrm{P}) / d^{2}\right)$, where $n=$ sample size, $p=$ proportion of sexual practice $<18$ years (taken as $53.3 \%$ according to reproductive health service utilization in Mizan-Tepi University students, Ethiopia, 2017 [3], $d=$ maximum allowable error (margin of error) $=0.05$, and $Z=$ value of standard normal distribution at $95 \%$ confidence level $(z=1.96)$.

By adding $10 \%$ nonresponse rate, the total sample size will be $382 * 10 \%=38$. Thus, the total sample size was $n=420$.

2.6. Sampling Techniques and Procedure. We have used multistage stratified sampling technique. In the study area, there were a total of four secondary schools. Sections from each school were selected with simple random sampling method. Then, they were allocated proportionately. From each section, students were picked by systematic sampling method. The samples were distributed proportionally based on probability proportional to size (PPS). Participants in each school were selected by using systematic sampling technique after calculating sampling interval $(K)$ for each school according to students' roll number in the class and the first student was selected by simple random method. 
$K=N / n f=3295 / 420=8$. So, every 5 individuals were selected until the sample size was completed.

\subsection{Variables}

2.7.1. Dependent Variables. The dependent variables included knowledge of reproductive health services, attitude towards reproductive health services, and practice of reproductive health services.

2.7.2. Independent Variables. The independent variables included sociodemographic factors, health care factors, social factors, and behavioral factors.

\subsection{Eligibility Criteria}

2.8.1. Inclusion Criteria. The inclusion criteria were Woldia town secondary school students who attend the class during data collection period and volunteers.

\subsubsection{Exclusion Criteria}

(i) Those who were not available during data collection period

(ii) Those who were physically and mentally not capable of being interviewed

\subsection{Operational Definitions}

2.9.1. Good Knowledge. Those students who answer mean and above the mean score of knowledge questions were categorized as knowledgeable while those students answer below the mean score were categorized under poor knowledge.

2.9.2. Good Attitude. Those students who answer mean and above the mean score of attitude questions were categorized as having good attitude while those students answer below the mean score were categorized as having poor attitude.

2.9.3. Good Practice. Those students who answer mean and above the mean score of practice questions were categorized as having good practice while those students who answer below the mean score were categorized as having poor practice.

2.10. Data Collection Tool and Procedure. Data was collected by an adapted, pretested, structured, and interviewer-administered questionnaire. The questionnaire was first developed in English and translated to Amharic language by an expert. It was translated back to English by an independent translator to check for consistency. An interview with adolescent of the index students was conducted at their secondary school.
2.11. Data Quality Control. To assure data quality, the data collection tool was pretested. Data collectors and the supervisor were trained on the data collection techniques. In addition, the completeness, accuracy, and consistency of the collected data were checked on daily basis during the data collection time. The supervisors and principal investigators closely followed the data collection process. The data was entered on daily basis and missing data was identified. Incomplete data or questioners that miss the major content were not included in the study.

2.12. Data Analysis and Presentation. Data was entered by using EpiData version 4.2 and was exported to SPSS version 24 for analysis. Descriptive statistics like frequency, proportions, mean, and standard deviation were computed to describe the study variable in relation to the population and were presented by tables and graphs. Bivariate and multivariable logistic regressions were carried out to see associations between dependent and independent variables. Those variables that have $p$ value $\leq 0.25$ were taken to the multivariable logistic regression model to adjust for possible confounders. The strength of association was declared at $p$ values $<0.05$. Finally, the result was compiled and presented using tables, graphs, and texts.

\section{Result}

All 420 respondents complete the questioner with the response rate of 100\%. Among these, 204 (48.6\%) were females. The majority of the respondents 238 (56.7\%) were within the age group of 15-19 years. Most of respondents were unmarried 384 (91.4\%) followed by having boy/girlfriend $231(55.0 \%)$ (Table 1$)$.

\subsection{Knowledge Level of Respondents on Reproductive Health} Issues. The prevalence of good knowledge was 204 (48.6\%). About 334 (79.5\%) respondents have awareness of pregnancy risk time. Three-fourths, 315 (75.0\%), of respondents ever heard of VCT and the majority 322 (76.7\%) of respondents ever heard about family planning method. One hundred sixteen $(27.76 \%)$ respondents have got information about reproductive health services from their parents followed by $101(24.16 \%)$ respondents who got from their teacher. The majority 292 (69.5\%) of participants knows injectable as ways of contraception followed by condom 222 (52.9\%). Regarding respondents' knowledge on STI, majority $362(86.2 \%)$ of respondents had ever heard about STIs. Of those heard about STI, 58 (13.8\%) participants have heard using radio/television. About 223 (53.1\%), 146 (34.8\%), and $123(29.3 \%)$ of respondents know the most known types of STI: syphilis, gonorrhea, and chancroid, respectively. About 273 (65\%), 163 (39\%), and 270 (61\%) of respondents know that STI manifested with genital discharge, genital ulcer, and pain during urination, respectively. Regarding knowledge about ways of HIV transmission, the majority 317 (75.5\%) of respondents knows that unsafe sexual intercourse is one way of HIV/AIDS transmission. Regarding respondents' knowledge on ways to prevent unwanted pregnancies, the 
TABLe 1: Sociodemographic characteristics of secondary school students in Woldia town, Amhara, Ethiopia, 2019.

\begin{tabular}{|c|c|c|c|}
\hline Characteristics & Category & Frequency & Percent \\
\hline \multirow{3}{*}{ Age } & $10-15$ & 50 & 11.9 \\
\hline & $15-19$ & 238 & 56.7 \\
\hline & $20-24$ & 132 & 31.4 \\
\hline \multirow{2}{*}{ Sex } & Male & 216 & 51.4 \\
\hline & Female & 204 & 48.6 \\
\hline \multirow{4}{*}{ Marital status } & Unmarried & 384 & 91.4 \\
\hline & Married & 21 & 5.0 \\
\hline & Divorced & 13 & 3.1 \\
\hline & Widowed & 2 & .5 \\
\hline \multirow{2}{*}{ Residence } & Urban & 304 & 72.4 \\
\hline & Rural & 116 & 27.6 \\
\hline \multirow{6}{*}{ Father's occupation } & Farmer & 159 & 159 \\
\hline & Civil servant & 131 & 131 \\
\hline & Merchant & 72 & 72 \\
\hline & Driver & 34 & 34 \\
\hline & Daily laborer & 4 & 4 \\
\hline & Others & 20 & 20 \\
\hline \multirow{3}{*}{ Wealth index } & High & 108 & 25.7 \\
\hline & Medium & 245 & 58.3 \\
\hline & Low & 67 & 16.0 \\
\hline \multirow{3}{*}{ Ethnicity } & Amhara & 398 & 94.8 \\
\hline & Tigri & 17 & 4.0 \\
\hline & Others & 5 & 1.2 \\
\hline \multirow{4}{*}{ Religion } & Muslim & 122 & 29.0 \\
\hline & Orthodox & 278 & 66.2 \\
\hline & Protestant & 14 & 3.3 \\
\hline & Others & 6 & 1.4 \\
\hline \multirow{2}{*}{ Educational level } & Grade 9 & 237 & 56.4 \\
\hline & Grade 10 & 183 & 43.6 \\
\hline \multirow{2}{*}{ Presence of RHS in school } & Yes & 286 & 68.1 \\
\hline & No & 134 & 31.9 \\
\hline \multirow{3}{*}{ Handling of RHS providers } & Good & 191 & 46 \\
\hline & Moderate & 176 & 41.9 \\
\hline & Bad & 51 & 12.1 \\
\hline \multirow{2}{*}{ Missed RHS required } & Yes & 262 & 62.4 \\
\hline & No & 158 & 37.6 \\
\hline \multirow{4}{*}{ Reason for not getting $\mathrm{RH}$} & Lack of money & 156 & 37.1 \\
\hline & Neighbors felt ashamed & 147 & 35.0 \\
\hline & Service providers refused & 77 & 18.3 \\
\hline & Clinic was closed & 40 & 9.5 \\
\hline \multirow{2}{*}{ Ever heard of YFRHS } & Yes & 261 & 62.1 \\
\hline & No & 159 & 37.9 \\
\hline \multirow{2}{*}{ Parents influence not to use RHS } & Yes & 270 & 64.3 \\
\hline & No & 150 & 35.7 \\
\hline \multirow{2}{*}{ Stigma attached to utilizing RHS } & Yes & 268 & 63.8 \\
\hline & No & 152 & 36.2 \\
\hline \multirow{2}{*}{ Cultural and religious influence } & Yes & 248 & 59.0 \\
\hline & No & 172 & 41.0 \\
\hline \multirow{2}{*}{ Have girl/boyfriend } & Yes & 231 & 55.0 \\
\hline & No & 189 & 45.0 \\
\hline & Yes & 150 & 35.7 \\
\hline Had sexual intercourse & No & 270 & 64.3 \\
\hline & No & 248 & 59.0 \\
\hline & Yes & 103 & 24.5 \\
\hline Chew chat & No & 317 & 75.5 \\
\hline & Yes & 122 & 29.0 \\
\hline Drink alcohol & No & 298 & 71.0 \\
\hline
\end{tabular}


TABLE 2: Knowledge of RHS among secondary school students in Woldia, North Wollo Zone, Ethiopia, 2019.

\begin{tabular}{|c|c|c|c|}
\hline Variables & Category & Frequency & Percent \\
\hline \multirow{2}{*}{ Aware ness of pregnancy risk time } & Yes & 334 & 79.5 \\
\hline & No & 86 & 20.5 \\
\hline \multirow{2}{*}{ RH information } & Yes & 298 & 71 \\
\hline & No & 122 & 29 \\
\hline \multirow{2}{*}{ Ever heard about family planning method } & Yes & 322 & 76.7 \\
\hline & No & 98 & 23.3 \\
\hline \multirow{2}{*}{ Ever heard of VCT } & Yes & 315 & 75.0 \\
\hline & No & 105 & 25.0 \\
\hline \multirow{5}{*}{ Source of information about $\mathrm{RH}$} & Parents & 116 & 27.76 \\
\hline & Peer & 99 & 23.76 \\
\hline & Teacher & 101 & 24.16 \\
\hline & Notice board & 71 & 17.06 \\
\hline & Mass media & 33 & 7.26 \\
\hline \multicolumn{4}{|l|}{ Ways of preventing unwanted pregnancy } \\
\hline \multirow{2}{*}{ Oral contraceptive pills } & Yes & 231 & 55.0 \\
\hline & No & 189 & 45.0 \\
\hline \multirow{2}{*}{ Condom } & Yes & 222 & 52.9 \\
\hline & No & 198 & 47.1 \\
\hline \multirow{2}{*}{ Injectable } & Yes & 292 & 69.5 \\
\hline & No & 128 & 30.5 \\
\hline \multirow{2}{*}{ IUCD } & Yes & 77 & 18.3 \\
\hline & No & 343 & 81.7 \\
\hline \multirow{2}{*}{ Sterilization } & Yes & 51 & 12.1 \\
\hline & No & 369 & 87.9 \\
\hline \multirow{2}{*}{ Abstain } & Yes & 99 & 23.6 \\
\hline & No & 321 & 76.4 \\
\hline \multirow{2}{*}{ Withdrawal } & Yes & 34 & 8.1 \\
\hline & No & 386 & 91.9 \\
\hline \multirow{2}{*}{ Safe period/abstain } & Yes & 61 & 14.5 \\
\hline & No & 359 & 85.5 \\
\hline \multirow{2}{*}{ Ever heard of STI } & Yes & 362 & 86.2 \\
\hline & No & 58 & 13.8 \\
\hline \multicolumn{4}{|l|}{ Most known types of STI } \\
\hline \multirow{2}{*}{ Gonorrhea } & Yes & 146 & 34.8 \\
\hline & No & 274 & 65.2 \\
\hline \multirow{2}{*}{ Syphilis } & Yes & 223 & 53.1 \\
\hline & No & 197 & 46.9 \\
\hline \multirow{2}{*}{ Chancroid } & Yes & 123 & 29.3 \\
\hline & No & 297 & 70.7 \\
\hline \multirow{2}{*}{ LGV } & Yes & 75 & 17.9 \\
\hline & No & 345 & 82.1 \\
\hline HIV/AIDS & Yes & 325 & 77.4 \\
\hline HIV/AIDS & No & 95 & 22.6 \\
\hline Symptoms of STI & & & \\
\hline Genital dischoroe & Yes & 273 & 65 \\
\hline Genital discharge & No & 147 & 35 \\
\hline & Yes & 163 & 39 \\
\hline Genital ulcer & No & 257 & 61 \\
\hline & Yes & 270 & 61 \\
\hline Pain during urination & No & 150 & 39 \\
\hline Ways of HIV/AIDS transmission & & & \\
\hline & Yes & 317 & 75.5 \\
\hline Unsafe sexual intercourse & No & 103 & 24.5 \\
\hline
\end{tabular}


TABLE 2: Continued.

\begin{tabular}{|c|c|c|c|}
\hline Variables & Category & Frequency & Percent \\
\hline \multirow{2}{*}{ Blood transfusion } & Yes & 228 & 54.3 \\
\hline & No & 192 & 45.7 \\
\hline \multirow{2}{*}{ Sharing of needle and syringes } & Yes & 290 & 69.0 \\
\hline & No & 130 & 31.0 \\
\hline \multirow{2}{*}{ During pregnancy and child birth } & Yes & 149 & 35.5 \\
\hline & No & 271 & 64.5 \\
\hline \multirow{2}{*}{ Through breast milk } & Yes & 131 & 31.2 \\
\hline & No & 289 & 68.8 \\
\hline \multirow{2}{*}{ Through mosquito and other insects' bite } & No & 324 & 77.1 \\
\hline & Yes & 96 & 22.9 \\
\hline \multirow{2}{*}{ Hand shaking or sharing foods } & No & 330 & 78.6 \\
\hline & Yes & 90 & 21.4 \\
\hline \multicolumn{4}{|l|}{ Ways of preventing unwanted pregnancy } \\
\hline \multirow{2}{*}{ Abstain } & Yes & 242 & 57.6 \\
\hline & No & 178 & 42.4 \\
\hline \multirow{2}{*}{ Condom } & Yes & 233 & 55.5 \\
\hline & No & 187 & 44.5 \\
\hline \multirow{2}{*}{ Pills/injectable } & Yes & 258 & 61.4 \\
\hline & No & 162 & 38.6 \\
\hline \multirow{2}{*}{ Abstain } & Yes & 242 & 57.6 \\
\hline & No & 178 & 42.4 \\
\hline
\end{tabular}

majority $258(61.4 \%)$ of respondents know pills/injectable, $233(55.5 \%)$ and condom $86(20.5 \%)$ as ways of prevention of unwanted pregnancy, respectively (Table 2).

\subsection{Factors Associated with Knowledge Level of Respondents on Reproductive Health Issues}

3.2.1. Bivariate and Multivariate Analysis of Knowledge on RH Issues and Associated Factors. In bivariate logistic regression analysis residence, educational level, handling of RHS providers, ever gone RHS institution, had information about RHS, having girl/boyfriend, missed RHS service, had RHS in school, chew chat, and stigma to utilize RHS were associated with knowledge level of respondents on reproductive health issues. In multivariate logistic regression residence, educational level, handling of RHS providers, ever gone RHS institution, missed RHS service, had RHS in school, chew chat, and stigma to utilize RHS were found to be significantly associated with the level of knowledge of respondents on reproductive health issues. Accordingly, the odds of good knowledge on reproductive health issues among respondents from urban residence $(\mathrm{AOR}=2.40,95 \% \mathrm{CI}(1.23$, 2.36)) were higher compared to those respondents from rural residences. Respondents who are grade 10 were 1.46 times more likely to have good level knowledge on $\mathrm{RH}$ issues compared to grade 9 respondents. The odds of good knowledge on reproductive health issues among respondents who get good handling from RHS providers $(\mathrm{AOR}=2.28$, $95 \%$ CI $(1.15,2.54))$ were higher compared to those who get bad handling from RHS providers. Respondents who ever gone to RHS and did not miss the service were 1.25 times more likely to have good knowledge of $\mathrm{RH}$ issues compared to those who missed the service. The odds of good knowledge on reproductive health issues among respondents who have RHS in their school $(\mathrm{AOR}=2.06,95 \% \mathrm{CI}(1.68,7.66))$ were higher compared to those who have not RHS in their school. Moreover respondents who live in a community with stigma to utilize RHS were $37 \%$ less likely to have good knowledge on $\mathrm{RH}$ issues compared to those who live in a community with no stigma to utilize RHS (Table 3 ).

\section{Discussion}

This institution-based descriptive cross-sectional study was conducted on 420 study participants to assess the magnitude and associated factors of knowledge on reproductive health services among secondary school students in Woldia town. Accordingly, the overall prevalence of good knowledge was $48.6 \%$. This finding is consistent with two studies conducted in Nigeria $[18,19]$. This might be due to the similarity of study subjects in both Nigerian studies, and our studies are conducted on adolescents. The magnitude is lower than that of the study conducted in Gondar University [20] and Wolaita Sodo University [21]. The possible reason could be the difference in the study population that the studies from Gondar and Wolaita Sodo University are conducted on university students who have better exposure on RH issues compared with our study subjects who are secondary school students having less information exposure. The high proportion health science students in their study may also be the possible reason. Students who come from urban areas are more likely to have good level of knowledge about HR issues than those who come from rural areas. This finding is in line with a study conducted in Wolaita Sodo University [21] and in Gondar University [20]. As evidenced from the Ethiopian 
TABLE 3: Factors associated with knowledge of RH issues among secondary school students in Woldia, North Wollo Zone, Ethiopia, 2019.

\begin{tabular}{|c|c|c|c|c|c|c|}
\hline \multirow[b]{2}{*}{ Exposure variable } & \multirow[b]{2}{*}{ Responses } & \multicolumn{2}{|c|}{ Knowledge level } & \multirow{2}{*}{$\begin{array}{l}\text { COR with } \\
95 \% \mathrm{CI}\end{array}$} & \multirow[b]{2}{*}{ AOR 95\% CI } & \multirow[b]{2}{*}{$p$ value } \\
\hline & & $\begin{array}{l}\text { Good knowledge } 204 \\
(48.6 \%)\end{array}$ & $\begin{array}{c}\text { Poor knowledge } 216 \\
(51.4)\end{array}$ & & & \\
\hline \multirow[t]{2}{*}{ Residence } & Urban & $137(32.6)$ & $167(39.8)$ & $\begin{array}{c}3.67(1.08, \\
2.57)\end{array}$ & $\begin{array}{c}2.40(1.23 \\
2.362)^{*}\end{array}$ & 0.024 \\
\hline & Rural & $67(16.0)$ & $49(11.7)$ & 1 & 1 & - \\
\hline \multirow{3}{*}{ Wealth index } & High & $47(11.2)$ & $61(14.5)$ & 1 & 1 & - \\
\hline & Medium & $125(29.8)$ & $120(28.6)$ & $\begin{array}{c}0.74(0.47 \\
1.17)\end{array}$ & $\begin{array}{c}0.96(0.58 \\
1.580)\end{array}$ & 0.868 \\
\hline & Low & $32(7.6)$ & $35(8.3)$ & $\begin{array}{c}0.84(0.46 \\
1.55) \\
\end{array}$ & $\begin{array}{l}1.18(0.60 \\
2.32) \\
\end{array}$ & 0.632 \\
\hline \multirow[b]{2}{*}{ Educational level } & Grade 9 & $102(24.3)$ & $135(32.1)$ & 1 & 1 & - \\
\hline & Grade 10 & $102(24.3)$ & $81(19.3)$ & $\begin{array}{l}1.67(1.13 \\
2.46) \\
\end{array}$ & $\begin{array}{c}1.46(1.16 \\
2.21)^{*}\end{array}$ & 0.036 \\
\hline \multirow[t]{2}{*}{ Had information about SRHS } & Yes & $152(36.2)$ & $182(43.3)$ & $\begin{array}{c}1.83(1.13,2 \\
.97)\end{array}$ & $\begin{array}{l}1.56(0.92 \\
2.63)\end{array}$ & .098 \\
\hline & No & $52(12.4)$ & $34(8.1)$ & 1 & 1 & - \\
\hline \multirow{3}{*}{ Handling of RHS providers } & Good & $84(20.0)$ & $108(25.8)$ & $\begin{array}{l}2.45(0.78 \\
2.69)\end{array}$ & $\begin{array}{l}2.28(1.15 \\
2.54)^{*}\end{array}$ & 0.047 \\
\hline & Moderate & $93(22.2)$ & $83(19.8)$ & $\begin{array}{l}1.00(0.54 \\
1.88)\end{array}$ & $\begin{array}{l}0.98(0.50 \\
1.91)\end{array}$ & 0.949 \\
\hline & $\mathrm{Bad}$ & $27(6.4)$ & $24(5.7)$ & 1 & 1 & 0.323 \\
\hline \multirow{2}{*}{$\begin{array}{l}\text { Ever gone RHS and missed the } \\
\text { service }\end{array}$} & Yes & $120(28.6)$ & $142(33.8)$ & 1 & 1 & - \\
\hline & No & $84(20.0)$ & 749 (17.6) & $1.34(90,2.00)$ & $\begin{array}{l}1.25(1.10 \\
5.94)^{*}\end{array}$ & 0.023 \\
\hline \multirow[t]{2}{*}{ Had RHS in school } & Yes & $121(28.8)$ & $143(34.0)$ & $\begin{array}{l}2.34(0.90 \\
2.00)\end{array}$ & $\begin{array}{c}2.06(1.68 \\
7.66)^{*}\end{array}$ & 0.011 \\
\hline & No & $83(19.8)$ & $73(17.4)$ & 1 & 1 & - \\
\hline \multirow[t]{2}{*}{ Is there stigma to utilize RHS? } & Yes & $138(32.9)$ & $130(31.0)$ & $\begin{array}{l}0.73(0.48 \\
1.08)\end{array}$ & $\begin{array}{l}0.63(0.41 \\
0.98)^{*}\end{array}$ & 0.041 \\
\hline & No & $66(15.7)$ & $86(20.5)$ & 1 & 1 & - \\
\hline \multirow[t]{2}{*}{ Do you have girl/boyfriend? } & Yes & $106(25.2)$ & $125(29.8)$ & $\begin{array}{l}1.27(0.86 \\
1.87)\end{array}$ & $\begin{array}{c}1.14(0.74 \\
1.77)\end{array}$ & 0.556 \\
\hline & No & $98(23.3)$ & $91(21.7)$ & 1 & - & - \\
\hline \multirow{2}{*}{$\begin{array}{l}\text { Did you ever had sexual } \\
\text { intercourse? }\end{array}$} & Yes & $67(16.0)$ & $83(19.8)$ & $\begin{array}{c}1.28(0.86 \\
1.91)\end{array}$ & $\begin{array}{c}0.98(0.61 \\
1.580)\end{array}$ & 0.935 \\
\hline & No & $137(32.6)$ & $133(31.7)$ & 1 & 1 & - \\
\hline \multirow{2}{*}{$\begin{array}{l}\text { Did your friends encourage you to } \\
\text { use RHS? }\end{array}$} & Yes & $77(18.3)$ & $95(22.6)$ & $10(0.88,1.91)$ & $\begin{array}{c}0.78(0.47 \\
1.28)\end{array}$ & 0.320 \\
\hline & No & $127(30.2)$ & $121(28.8)$ & 1 & 1 & - \\
\hline \multirow[t]{2}{*}{ Did you chew chat? } & Yes & $36(8.6)$ & $67(16.0)$ & $\begin{array}{l}2.10(1.32 \\
3.33)\end{array}$ & $\begin{array}{l}1.85(1.01 \\
3.38)^{*}\end{array}$ & 0.047 \\
\hline & No & $168(40.0)$ & $149(35.5)$ & 1 & 1 & - \\
\hline \multirow{2}{*}{ Did you drink alcohol? } & Yes & $47(11.2)$ & 75 (17.9) & $\begin{array}{c}1.78(1.16 \\
2.73)\end{array}$ & $\begin{array}{c}1.31(0.75 \\
2.30)\end{array}$ & 0.345 \\
\hline & No & $157(37.4)$ & $141(33.6)$ & 1 & 1 & - \\
\hline
\end{tabular}

Note. ${ }^{*} p$ value $<0.05, \mathrm{CI}=$ confidence interval, $\mathrm{COR}=$ crude odds ratio, and $\mathrm{AOR}=$ adjusted odds ratio.

demographic and health survey, people from rural areas are less likely to read a newspaper, listen to the radio, or watch television; therefore, their knowledge about HR issues can be negatively affected [22]. Respondents who are grade 10 were more likely to have good level of knowledge on $\mathrm{RH}$ issues compared to grade 9 respondents. This finding is supported by another studies in Ethiopia $[22,23]$. This might be due to the fact that as the level of education increases, the information exposure about $\mathrm{RH}$ issues and age maturity will improve the knowledge level of students. The odds of good knowledge on reproductive health issues among respondents who get good handling from RHS providers were higher compared to those who get bad handling from RHS providers. This might be due the fact that good handling of RH service providers would help the participants to have positive attitude towards SRH services and they ask for information regarding $\mathrm{RH}$ issues and they will listen to and apply the counseling given by the providers [23]. The odds of good knowledge on reproductive health issues among respondents who have RHS in their school were higher 
compared to those who have not RHS in their school. This finding is supported by the study conducted in northeast Ethiopia [23]. The possible justification for this might be those service providers in school will give counseling on $\mathrm{RH}$ issues in addition to giving treatment. In these settings, students are more likely to get education about SRHRs while they visit the clinic for other RH services which boosts their knowledge. The odds of good level of knowledge on $\mathrm{RH}$ issues are lower among those adolescents who have stigma compared to those who have no stigma have higher risk of low level to poor $\mathrm{RH}$ utilization than their counterparts. This result is similar with Nigeria and Nepal $[24,25]$. This might be due to the fact that those who were stigmatized lack proper information on safe sex as well as they cannot communicate their problems with each other in fear of social stigma and less likely to get the opportunity to $\mathrm{RH}$ service and counseling.

4.1. Strength and Limitation. The study used adapted standardized questionnaires which increase its validity. Adequate sample size was employed with a high response rate. The investigators made a lot of effort to maintain the quality of the data, mainly through a pretest, frequent field supervisions, and training of data collectors. However, the study is not free from error. It may introduce social desirability and recall bias. In addition, the study was not supplemented with any qualitative data. As being crosssectional, this work has not shown cause-effect relationships.

\section{Conclusion}

The level of knowledge of respondents on reproductive health issues in the study area was low. Residence, educational level, handling of RHS providers, ever gone RHS institution, missed RHS service, had RHS in school, chew chat, and stigma to utilize RHS were found to be significantly associated with the level of knowledge of respondents on reproductive health issues. Hence, strengthening women's education and establishing $\mathrm{RH}$ service and $\mathrm{RH}$ issues-related education shall be available among all faculties giving emphasis to students from rural areas. Information about reproductive health issues should be provided to adolescents through medical schools' curricula.

\section{Data Availability}

The data used to support the findings of this study are available from the corresponding author upon request.

\section{Ethical Approval}

The study was carried out after getting permission from the ethical review committee of Woldia University, College of Health Science.

\section{Consent}

Written informed consent for participation in the study was obtained from their parent or guardian for participants who were children (under 16 years old). A letter of support which indicates the objective of the study was written to each secondary school. The purpose of the study was explained to the participants and data was collected after full informed written consent obtained and confidentiality of the information was also maintained by omitting their names and personal identification.

\section{Conflicts of Interest}

The authors declare there are no conflicts of interest regarding the publication of this paper.

\section{Authors' Contributions}

$\mathrm{BB}, \mathrm{KH}, \mathrm{MA}, \mathrm{HF}$, and TM developed the study design and protocol, literature review, selection of studies, quality assessment, data extraction, statistical analysis, interpretation of the data and developing the initial drafts of the manuscript, and prepared the final draft of the manuscript. All the authors read and approved the final manuscript.

\section{References}

[1] K. E. McPherson, S. Kerr, E. McGee et al., "The association between social capital and mental health and behavioural problems in children and adolescents: an integrative systematic review," BMC Psychology, vol. 2, no. 1, p. 7, 2014.

[2] A. Motuma, T. Syre, E. Gudina, and A. Kenay, "Utilization of youth friendly services and associated factors among youth in Harar town, east Ethiopia: a mixed method study," BMC Health Services Research, vol. 16, no. 1, p. 272, 2016.

[3] Y. Yemane, R. Gezahagn, M. Yechale et al., "Assessment of Knowledge, Attitude and Practice towards Reproductive Health Service Among Mizan Tepi Universtiy Tepi Campus Students, Sheka Zone, South Nations Nationalities and Peoples Regional State, South West Ethiopia," Journal of Hospital and Medical Management, vol. 3, no. 1, 2017.

[4] A. M. Lutende, "Adolescents' awareness of youth friendly reproductive health services in public health facilities: the case of Ilala municipality," Dissertation Submitted in Partial Fulfillment of the Requirements for the Degree of Master of Social Work, Open University of tanzania, Dar es Salaam, Tanzania, 2016.

[5] P. McGorry, T. Bates, and M. Birchwood, "Prevention, innovation and implementation science in mental health: the next wave of reform," British Journal of Psychiatry, vol. 202, no. 54, pp. 3-4, 2013.

[6] K. Kahsay, S. Berhe, and M. Alemayehu, "utilization of youth friendly services and associated factors in mekelle town, tigray, northern ethiopia 2016," International Journal of Therapeutic Applications, vol. 33, pp. 49-59, 2016.

[7] I. Ojong, M. Akpan, M. O. Alasia, and F. Nlumanze, "A comparative study on reproductive health awareness among urban and rural secondary school students in cross river state, Nigeria," Journal of Research in Nursing and Midwifery, vol. 3, no. 1, pp. 21-25, 2014.

[8] S. Akhter, Knowledge, Attitudes and Practices on Reproductive Health and Rights of Urban and Rural Women in Bangladesh, Ubinig Publisher, Dhaka, Bangladesh, 2007.

[9] A. A. Abajobir and A. Seme, "Reproductive health knowledge and services utilization among rural adolescents in east Gojjam zone, Ethiopia: a community-based cross-sectional 
study," BMC Health Services Research, vol. 14, no. 1, p. 138, 2014.

[10] A. Y. Alliance and P. Finder, Youth Friendly Sexual and Reproductive Health Services: An Assessment of Facilities, Pathfinder International, Dar es Salaam, Tanzania, 2003.

[11] R. L. Coley, B. L. Medeiros, and H. S. Schindler, "Using sibling differences to estimate effects of parenting on adolescent sexual risk behaviors," Journal of Adolescent Health, vol. 43, no. 2, pp. 133-140, 2008.

[12] HIV/AIDS, JUNPo. Ethical Considerations in HIV Preventive Vaccine Research: UNAIDS Guidance Document, UNAIDS, Geneva, Switzerland, 2000.

[13] A. Tegegn, M. Yazachew, and Y. Gelaw, "Reproductive health knowledge and attitude among adolescents: a community based study in Jimma Town, Southwest Ethiopia," Ethiopian Journal of Health Development, vol. 22, no. 3, 2008.

[14] G. Barnabas, E. Pegurri, H. H. Selassie, W. Naamara, and S. Zemariam, "The HIV epidemic and prevention response in Tigrai, Ethiopia: a synthesis at sub-national level," BMC Public Health, vol. 14, no. 1, p. 628, 2014.

[15] W. B. Group, World Development Indicators 2014, World Bank Publications, Washington, DC, USA, 2014.

[16] T. Kaneda, G. Dupuis, and K. Bietsch, World Population Data Sheet, Vol. 13, Population Reference Bureau, Washington, DC, USA, 2015.

[17] X. Liu, L. L. Liang, and E. Liu, "Science education research in China: challenges and promises," International Journal of Science Education, vol. 34, no. 13, pp. 1961-1970, 2012.

[18] M. Egemba and A. Ajuwon, "Knowledge and perceptions of reproductive rights among female postgraduate students of the university of ibadan, Nigeria," African Journal of Biomedical Research, vol. 18, no. 2, pp. 95-107, 2015.

[19] M. A. Ogunlayi, "An assessment of the awareness of sexual and reproductive rights among adolescents in South Western Nigeria," African Journal of Reproductive Health, vol. 9, no. 1, pp. 99-112, 2005.

[20] K. Gebresilassie, M. Boke, M. Yenit, and A. Baraki, "Knowledge level and associated factors about sexual and reproductive health rights among University of Gondar students, Gondar Ethiopia," International Journal of Sexual and Reproductive Health Care, vol. 2, no. 1, pp. 16-20, 2019.

[21] Y. M. Adinew, A. G. Worku, and Z. B. Mengesha, "Knowledge of reproductive and sexual rights among University students in Ethiopia: institution-based cross-sectional," BMC International Health and Human Rights, vol. 13, no. 1, p. 12, 2013.

[22] E. Edhs, "Demographic and health survey 2016: key indicators report," The DHS Program ICF, vol. 363, p. 364, 2016.

[23] M. Ayalew, D. Nigatu, G. Sitotaw, and A. Debie, "Knowledge and attitude towards sexual and reproductive health rights and associated factors among Adet Tana Haik College students, Northwest Ethiopia: a cross-sectional study," BMC Research Notes, vol. 12, no. 1, p. 80, 2019.

[24] A. G. Nmadu and S. Mohamed, "Access and utilization of reproductive health services among adolescents in kaduna," Master's thesis, University of Western Cape, Cape Town, South Africa, 2017.

[25] P. Khanal, Adolescents knowledge and perception of sexual and reproductive health and services-a study from Nepal, University of Eastern Finland, vol. 1, p. 78, Kuopio, Finland, 2016. 